\title{
OPTIMALISASI PEMANFAATAN MEDIA INTERNET DALAM PEMBELAJARAN MELALUI BLENDED LEARNING
}

\author{
Ratna Tiharita \\ Lecturer Economics Education Program FKIP Unswagati - Cirebon
}

\begin{abstract}
Abstrak
Pemanfaatan media teknologi informasi dan komunikasi dalam dunia pendidikan menjadi keharusan agar dapat merubah sistem pembelajaran yang konvensional atau tradisional. Internet menjadi salah satu media dan bahan belajar yang sangat kaya informasi, dan multi konten. Pada dasarnya internet merupakan media yang baik apabila dimanfaatkan secara benar dan tepat. Beragamnya konten yang tersedia di internet tentu merupakan sebuah ancaman juga bagi perkembangan siswa. Sebagai upaya untuk menyeimbangkan pembelajaran agar tetap kontekstual, terarah, dan berbasis teknologi informasi, dikembangkanlah sebuah pembelajaran campuran yang memadukan antara pembelajaran elearning dengan pembelajaran tradisional, yang disebut Blended Learning. Melalui hasil kajian teori dan eksperimen yang telah dilakukan, dalam tulisan ini penulis menyatakan penegasan bahwa penggunaan internet dalam pembelajaran dapat di optimalkan melalui model pembelajaran Blended Learning.
\end{abstract}

Kata Kunci : Blended, Learning, Internet, Teknologi.

\section{Pendahuluan}

Saat ini orientasi mengarah kepada penggunaan jaringan internet, semua aspek dalam kehidupan manusia dioptimalkan melalui akses internet, rasanya semua orang perlu untuk dapat menggunakan internet. Begitu pula dengan dunia pendidikan, internet diperlukan untuk melengkapi kekurangan yang timbul dalam pembelajaran. Penggunaan teknologi informasi dalam bidang pendidikan memberikan pengaruh yang sangat besar. Pembelajaran yang dilakukan saat ini dipastikan akan terpengaruh oleh teknologi informasi baik pembelajaran yang mengandung atau disesain khusus seperti e-learning maupun pembelajaran yang dilakukan seperti biasa.

Menurut Riyana (2010) dalam proses pembelajaran karena adanya internet akan terjadi: (a) bergesernya pendidikan dari sistem pembelajaran yang berorientasi pada guru (teacher centered learning) ke sistem yang berorientasi pada peserta didik (student centered learning), (b) tumbuh dan makin memasyarakatnya pendidikan terbuka dan jarak jauh, (c) semakin banyaknya pilihan sumber belajar yang tersedia.

Kusairi (2011) menambahkan ada tiga pergeseran dalam proses pembelajaran akibat perkembangan teknologi komunikasi yaitu: (a) pergeseran dari ruang kelas ke dimana dan kapan saja, (b) pergeseran dari kertas ke online, dan (c) pergeseran fasilitas fisik ke fasilitas 
jaringan kerja. Dengan adanya teknologi informasi ini guru dapat memberikan layanan tanpa harus berhadapan langsung dengan peserta didik, demikian pula peserta didik dapat memperoleh informasi dalam lingkup yang luas dari berbagai sumber melalui ruang dunia maya dengan menggunakan komputer atau internet.

Pemanfaatan teknologi dalam dunia pendidikan menjadi keharusan agar dapat merubah sistem pembelajaran yang konvensional atau tradisional, sehingga guru tidak hanya menjelaskan di depan kelas dan siswa mendengarkan saja. Interaksi guru dan siswa dalam pembelajaran menjadi pola modern yang bermedia teknologi informasi dan komunikasi. Media komputer dengan jaringan internetnya menjadi perangkat wajib dalam memunculkan elearning.

Internet seolah menjadi jalan tengah bagi kurikulum 2013 yang menuntut terjadinya pembelajaran yang sangat kontekstual, luas tapi tersusun. Pembelajaran menggunakan kurikulum 2013 disebut memiliki perbedaan pada pembelajaran pada umumnya dimana siswa harus lebih aktif, pembelajaran difokuskan kepada kebutuhan dan kesiapan siswa dalam kebutuhan materi. Penggunaan bahan ajar dapat diperluas salah satunya dengan mendapatkan atau membuat akses dengan e-learning. Pembelajaran dengan menggunakan teknologi informasi yang salah satunya melalui internet menjadi salah satu cara belajar dan bahan belajar yang mudah dan murah dalam penerapan kurikulum 2013. Dengan adanya internet pembelajaran bisa diseting menggunakan fasilitas tersebut. Internet merupakan bahan belajar yang sangat kaya pengetahuan, semua jenis kontent ada disana, tentu internet melalui e-learning merupakan salah satu sumber belajar yang dapat diakses oleh siapa saja termasuk siswa. Dengan adanya pemanfaatan internet siswa dapat mencari informasi dan mempersiapkan pengetahuannya dalam proses belajar.

Menurut Mekhlafi (2004:17) menyatakan bahwa pemanfaatan teknologi komunikasi dan informasi dalam pembelajaran memiliki dampak positif terhadap performasi dan prestasi belajar peserta didik. Pembelajaran dengan pemanfaatan internet mampu menumbuhkan kemandirian siswa untuk mengkonstruksi sendiri pengetahuannya, ditunjukkan dengan adanya peningkatan penguasaan konsep, peningkatan generik sains dan diharapkan siswa memberikan tanggapan yang baik.

Pada dasarnya internet merupakan media yang baik apabila dimanfaatkan secara benar dan tepat. Namun penggunaan internet di kalangan pelajar belum dapat dikatakan baik dan benar, karena mereka belum mendapatkan pemahaman mengenai pemanfaatan penggunaan internet yang tepat. Kondisi yang terjadi banyak siswa yang ketika mereka menggunakan internet mereka tidak memanfaatkan media tersebut dengan baik akan tetapi digunakan untuk kegiatan yang tidak memberikan pengetahuan buat siswa. Tidak sedikit 
siswa yang justru memanfaatkan internet untuk hal-hal yang tidak baik seperti bermain game, membuka situs terlarang, kontent yang negatif, dan lain-lain.

Beragamnya konten yang tersedia di internet tentu merupakan sebuah ancaman juga bagi perkembangan siswa. Oleh karena itu peran guru tetap menjadi yang terdepan dalam mengarahkan kegiatan siswa kedalam proses pembelajaran yang seharusnya Internet memberikan informasi yang sangat banyak namun perlu diklarifikasi ulang oleh seorang guru karena kontent yang ada dalam internet belum dapat dipertanggungjawabkan secara akademik dan ilmiah.

Guru melakukan klarifikasi kepada siswa mengenai informasi dan pemanfaatan internet agar informasi yang siswa dapatkan menjadi valid dan jauh dari hal-hal yang tidak bermakna (HOAX). Peran guru dilakukan dalam sebuah kelas dalam pembelajaran konvensional, hal ini dilakukan sebagai penyeimbang agar proses pembelajaran dapat dilaksanakan dengan baik dan sesuai dengan tujuan. Sebagai upaya untuk menyeimbangkan pembelajaran agar tetap kontekstual, terarah, dan berbasis teknologi informasi, dikembangkanlah sebuah pembelajaran campuran yang memadukan antara pembelajaran elearning dengan pembelajaran tradisional, salah satu model pembelajaran yang mengakomodir hal ini adalah pembelajaran Blended Learning.

Blended Learning yaitu pembelajaran yang mengkombinasikan pembelajaran tatap muka dengan pembelajaran online. Blended Learning yang mengkombinasikan metode tatap muka dan e-learning dapat melibatkan peserta didik secara aktif dan memungkinkan peserta didik mendapat umpan balik. Menurut Rahayu \& Nuryata (2010) bahwa pembelajaran blended mengkombinasikan metode pendidikan konvensional (tatap muka) dengan pembelajaran yang ditunjang dengan adanya teknologi.

\section{Blended Learning dan Hasil Belajar}

Pembelajaran online adalah pembelajaran yang dilakukan dengan mengandalkan pada sumber-sumber informasi yang tersedia pada jaringan internet. Dari konsep ini maka jelas pembelajaran online erat kaitannya dengan pemanfaatan internet sebagai sumber belajar. Perkembangan teknologi informasi dewasa ini, berdampak pada terjadinya perubahan peranan guru dan perubahan pengelolaan pembelajaran, yang kemudian bermuara pada perubahan paradigma tentang mengajar.

Proses pembelajaran di sekolah pada akhirnya bertujuan ingin mencapai tujuan pembelajaran yang diharapkan, yaki hasil belajar. Hasil belajar merupakan ukuran tingkat pencapaian tujuan pengajaran. Apabila tujuan pembelajaran telah tercapai maka yang didapat berupa hasil belajar. Jadi dengan kata lain kita dapat mengetahui apakah tujuan pembelajaran kita telah tercapai atau belum dengan melihat hasil belajar siswa. 
Menurut Gagne (1997) hasil belajar merupakan suatu gambaran hasil dari tujuan-tujuan yang harus dicapai dalam pembelajaran suatu konsep tertentu telah tercapai. Hasil belajar yaitu hasil tes kognitif (penguasaan materi) yang dicapai siswa setelah mengalami proses belajar mengajar pada materi buku besar yang ditunjukkan oleh nilai tes awal dan tes akhir. Hasil belajar dapat diketahui dengan cara memberikan penilaian terhadap individu yang belajar.

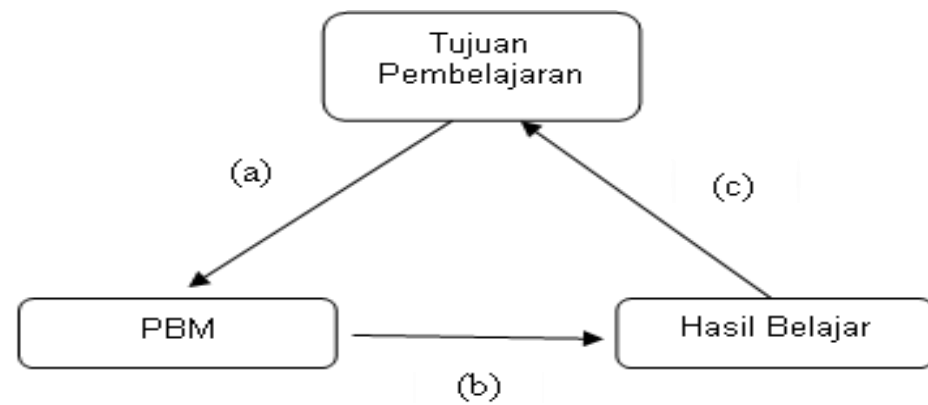

(b)

\section{Gambar 1 \\ Pencapaian Tujuan dalam Proses Belajar Mengajar}

Berdasarkan gambar di atas dapat dijelaskan bahwa seberapa besar tujuan pembelajaran yang dapat dicapai oleh siswa dalam bentuk hasil belajar setelah siswa menempuh proses pembelajaran. Hasil belajar tidak hanya untuk mengetahui tercapai tidaknya tujuan pembelajaran tetapi sebagai umpan balik upaya memperbaiki proses pembelajaran.

Dalam hal ini proses pembelajaran dengan menggunakan model pembelajaran bauran tipe (Blended Learning) dengan tujuan mendapatkan hasil pembelajaran yang diinginkan sesuai dengan KKM yang ditentukan. Model pembelajaran Blended Learning merupakan kegiatan pembelajaran yang menekankan pada proses belajar yang di bantu dengan menggunakan media internet. Proses belajar itu sendiri biasanya dilakukan melalui pemberian tugas yang diberikan oleh guru kepada siswa. Model pembelajaran Blended Learning adalah suatu model pembelajaran yang menitik beratkan studi individual, dalam proses pembelajaran dimana siswa mencari materi pembelajaran yang terdapat dalam media internet.

Korelasi berdasarkan model tersebut yang akan diimplementasikan dalam kegiatan pembelajaran terutama dalam mata pelajaran Ekonomi sehingga siswa dapat mendapatkan pengetahuan yang lebih setelah mencari materi melalui media internet. Berdasarkan model Blended Learning yang akan diimplementasikan tersebut harus meliputi pengalaman belajar siswa yang belum pernah mendapatkan model pembelajaran tersebut guna untuk melihat perkembangan hasil belajar kognisi siswa yang bertujuan untuk menemukan kemampuan pengetahuan siswa. 
Kusairi (2011) menyebutkan bahwa pengembangan dan penelitian tentang Blended Learning telah banyak dilakukan para ahli seperti Block dkk (2008), Hartono \& Rustaman (2008), Melton dkk (2009), Levenberg \& Caspi (2010), Amiruddin \& Santosa (2010), Husni dkk (2010), Bawaneh (2011), Neumann dkk (2011), Chen \& Keith (2007). Melton dkk (2009) hasil dari pengembangan disebutkan bahwa Blended Learning lebih disukai daripada kelas tradisional karena Blended Learning memberikan kepuasan. Senada dengan hal ini Graham dkk (2005) menyatakan Blended Learning dapat meningkatkan pedagogik, akses dan fleksibilitas, serta efektivitas biaya.

\section{Hasil Kajian \& Pembahasan}

Pembahasan dilakukan dengan berfokus kepada kajian literatur dan pengalaman penulis, serta hasil eksperimen yang dibimbing dan diobservasi oleh penulis. Respon siswa dalam pelaksanaan pembelajaran blended learning menunjukan respon yang baik, mereka tertarik dan termotivasi dengan dilakukannya pembelajaran blended learning. Hal tersebut diperoleh dari hasil pengisian angket respon siswa yang dilakukan setelah kegiatan eksperimen, digunakan 15 pertanyaan yang berisikan tentang respon mereka belajar dengan menggunakan model Blended Learning. Berdasarkan hasil rekapitulasi diperoleh sebagai berikut :

Tabel 1

Hasil Perhitungan Angket

\begin{tabular}{|c|c|c|c|c|c|c|}
\hline \multirow{2}{*}{$\begin{array}{c}\text { No. } \\
\text { Item }\end{array}$} & \multicolumn{7}{|c|}{ ALTERNATIF JAWABAN } & \multirow{2}{*}{ Skor } \\
\cline { 2 - 6 } & $\mathbf{5}$ & $\mathbf{4}$ & $\mathbf{3}$ & $\mathbf{2}$ & $\mathbf{1}$ & \\
\hline 1 & 4 & 19 & 9 & 1 & 0 & 125 \\
\hline 2 & 7 & 24 & 1 & 1 & 0 & 136 \\
\hline 3 & 9 & 20 & 4 & 0 & 0 & 137 \\
\hline 4 & 6 & 23 & 2 & 2 & 0 & 132 \\
\hline 5 & 7 & 11 & 13 & 2 & 0 & 122 \\
\hline 6 & 6 & 20 & 4 & 2 & 1 & 127 \\
\hline 7 & 11 & 18 & 4 & 0 & 0 & 139 \\
\hline 8 & 8 & 21 & 3 & 1 & 0 & 135 \\
\hline 9 & 6 & 18 & 9 & 0 & 0 & 129 \\
\hline 10 & 5 & 18 & 5 & 2 & 3 & 119 \\
\hline 11 & 7 & 15 & 11 & 0 & 0 & 128 \\
\hline 12 & 9 & 22 & 2 & 0 & 0 & 139 \\
\hline 13 & 5 & 24 & 4 & 0 & 0 & 133 \\
\hline 14 & 6 & 22 & 3 & 2 & 0 & 131 \\
\hline 15 & 7 & 20 & 6 & 0 & 0 & 133 \\
\hline & & & \multicolumn{3}{c}{ Total Skor } & 1965 \\
\hline
\end{tabular}

Menurut tabel di atas, jika skor total angket dihitung berdasarkan perhitungan perbandingan skor yang dicapai dengan skor ideal, skor ideal untuk variabel tersebut adalah 
2475. Sementara jumlah skor capaian adalah 1965, apabila dikonversi kedalam persentase dan kriterium adalah 1965/2475 x 100\% = 79,39\%. Apabila digambarkan dalam skor kriterium adalah sebagai berikut:

\begin{tabular}{|c|c|c|c|c|c|}
\hline 0 & 20 & 40 & 60 & 80 & 100 \\
\hline & $\begin{array}{l}\text { Sangat } \\
\text { Rendah }\end{array}$ & Rendah & Sedang & Tinggi & $\begin{array}{c}\text { Sangat } \\
\text { Tinggi }\end{array}$ \\
\hline & & & ar & 79 & \\
\hline
\end{tabular}

\section{Kriterium Optimalisasi Penggunaan Internet menggunakan Blended Learning}

Berdasarkan kriterium tersebut tergambarkan bahwa berdasarkan respon siswa optimalisasi penggunaan internet dalam pembelajaran blended learning tergolong tinggi.

Kemudian, berdasarkan hasil eksperimen terjadi peningkatan hasil belajar dikarenakan penerapan Blended Learning. Hal tersebut diketahui dari data hasil belajar berikut ini :

\section{Tabel 2}

Data hasil belajar kelas exsperimen

\begin{tabular}{|c|c|c|c|c|}
\hline & Pre-test & $\begin{array}{c}\text { Post- } \\
\text { test }\end{array}$ & N-gain & Indeks \\
\hline Jumlah & 1665 & 2650 & 20 & \multirow{2}{*}{ Sedang } \\
\hline Rerata & 50.45 & 80.30 & 0.59 & \\
\hline
\end{tabular}

Hasil Belajar siswa meningkat karenadengan dilaksanakannya pembelajaran model blended learning ini hal tersebut diperoleh dari hasil nilai hasil belajar siswa yang secara keseluruhan mengalami kenaikan, kenaikan terbesar yakni 0,92 yaitu peningkatan hasil belajar dari skor 35 ke 95 kenaikan terendah yakni sebesar 0,20 yaitu dari skor 50 ke 60 . Berdasarkan hasil rekapitulasi rata-rata kenaikan hasil belajar dari adalah sebesar 0,59.

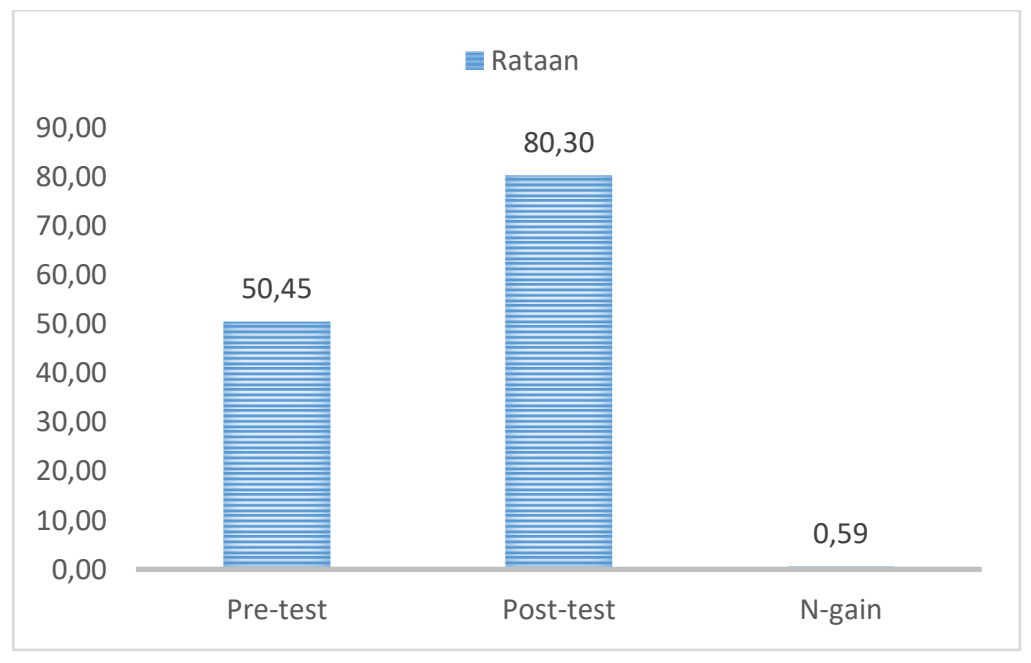




\section{Gambar 3}

\section{Hasil belajar Siswa}

Berdasarkan Grafik di atas menunjukan hasil belajar awal rata-rata 50,45 dan hasil belajar akhir dengan nilai 80,30 dan nilai gain 0,59 (ketegori sedang). Artinya terdapat kenaikan hasil belajar ekonomi siswa sebelum dan sesudah menggunakan metode Blended learning sebesar rata-rata 0,59 atau $59 \%$ dari nilai awal siswa.

\section{Simpulan}

Berdasarkan hasil kajian dan pembahasan penulis menyimpulkan bahwa pembelajaran Blended learning dapat mengoptimalkan penggunaan internet secara tepat guna, hal tersebut disimpulkan dengan berdasar kepada :

1. Respon siswa pelaksanaan pembelajaran blended learning menunjukan respon yang baik, mereka tertarik dan termotivasi dengan dilakukannya pembelajaran blended learning, dengan dilakukannya model pembelajaran blended learning mereka mendapatkan informasi yang tepat guna yang berfungsi sebagai bahan dalam pembelajaran.

2. Hasil belajar siswa dengan menggunakan blended learning memiliki hasil belajar yang lebih baik. Hal tersebut dikarenakan mereka betul-betul secara aktif menjadi sentral dalam pembelajaran, mereka mengkontruksi pengetahuan awal mereka dan diklarifikasi oleh penegasan dalam pembelajaran konvensional sehingga mereka memahami betul manfaat dari internet yang berdampak pada peningkatan hasil belajar mereka. 


\section{Daftar Pustaka}

Garrison, D. R., \& Vaughan, N. D. (2008). Blended learning in higher education: Framework, principles, and guidelines. John Wiley \& Sons.

Riyana, C. (2009). Teknologi Informasi dan Komunikasi dalam Pendidikan.

Kusairi, S. (2011, November). Implementasi Blended Learning. In Makalah (Disajikanpada Seminar Nasional Blended Learning tanggal 13 November 2011 di UniversitasNegeri Malang).

Utomo, J. (2001, April). Dampak Internet Terhadap Pendidikan: Transformasi atau Evolusi. In Seminar Nasional Universitas Atma Jaya Yogyakarta (Vol. 7).

Rosenberg, M. J. (2001). E-learning: Strategies for delivering knowledge in the digital age (Vol. 9). New York: McGraw-Hill.

Driscoll, M. (2002). Blended learning: Let's get beyond the hype. E-learning, 1(4), 1-4.

Sjukur, S. B. (2013). Pengaruh Blended Learning Terhadap Motivasi Belajar dan Hasil Belajar Siswa di Tingkat SMK. Jurnal Pendidikan Vokasi, 2(3).

Rahayu and Nuryata. (2010).Media Pembelajaran. Jakarta: Gramedia. 